\title{
A Study of the Role of 180W XPS Lithium Triborate Laser in the Treatment of Patients With Lower Urinary Tracts Symptoms Due to Benign Prostatic Hyperplasia
}

\author{
Omar Salim Akhtar ${ }^{*}$, Shailesh Raina ${ }^{2}$ \\ 'Department of Urology, Super Specialties Hospital, Government Medical College, Srinagar - J\&K - 190010, India \\ ${ }^{2}$ Director of Urology and Robotics, Jaslok Hospital \& Research Centre, Mumbai - 400026, Maharashtra, India
}

\author{
*Correspondence to \\ Omar Salim Akhtar, \\ Lecturer, Department of Urology \\ Super Specialties Hospital, \\ Government Medical College, \\ Srinagar - J\&K - 190010, \\ India \\ Tel: +919987633365; \\ Email: omarakhtar@hsshcc.org
}

Published online 17 September 2018

\begin{abstract}
Introduction: Benign prostatic hyperplasia $(\mathrm{BPH})$ is a disease of the prostate commonly seen in elderly males known to cause lower urinary tract symptoms (LUTS) that may require surgery as a part of treatment. Transurethral resection of the prostate (TURP) is considered the gold standard of surgical treatment, but it is not without complications. Laser photoselective vaporisation of the prostate (PVP), introduced in 1998 as an $80 \mathrm{~W}$ Nd:YAG laser which passed through a KTP (potassium-titanylphosphate) crystal, emerged as a safe alternative to TURP in selected cases. A recent upgrade to the Greenlight XPS $180 \mathrm{~W}$ powered with an LBO (lithium triborate) crystal has been available for use since 2012. Data on the use of this new upgrade is still being collected and analysed, especially in patients with large prostates or high risk cases. We analysed cases done at Jaslok Hospital over a 2-year period. Methods: A total of 34 patients who underwent Laser PVP using XPS 180W for LUTS due to BPH at Jaslok Hospital were part of this study. We analysed the pre- and postoperative variables and the intraoperative parameters of all patients.

Results: The XPS 180W was found to be safe and efficacious. Eighteen patients were high-risk cases, classified as ASA (American Society of Anesthesiologists) Classes 3 and 4. Average postoperative catheter duration was 40.18 hours. In prostates of size $<80 \mathrm{~mL}$, an average of $229 \mathrm{~kJ}$ of energy was used. In large prostates (>80 mL), an average of $390 \mathrm{~kJ}$ of energy was used. No major complications were seen in any of the high-risk patients, classified as Clavien Dindo Class 3 and 4 . The postoperative drop in IPSS (International Prostate Symptom Score) was 8.7.

Conclusion: We found that Green Light Laser XPS $180 \mathrm{~W}$ may be used for large (>80 g) prostates, hitherto an indication for open surgery, and that it may be used in high-risk patients, who were otherwise unfit for TURP. It is safe and efficacious. Further, multicenter trials are required to confirm the findings.

Keywords: LUTS; BPH; GreenLight ${ }^{\mathrm{TM}}$ Laser; PVP; XPS 180W; Laser Prostatectomy.
\end{abstract}

\section{Introduction}

Benign prostatic hyperplasia (BPH) is a commonly seen problem of adult males, characterised by bladder outlet obstruction and varying degrees of lower urinary tract symptoms (LUTS). ${ }^{1}$ Open prostatectomy (OP) for large glands $(>80 \mathrm{~mL})$ is considered for treatment of patients in whom medical therapy has failed to alleviate symptoms of BPH. ${ }^{2}$ For smaller glands ( $\left.>30 \mathrm{~mL}-80 \mathrm{~mL}\right)$ in patients in whom medical therapy has failed, transurethral resection of the prostate (TURP) is recommended. However, TURP is not without complications. A recent review of over 10000 patients showed complications of TURP include failure to void ( $4.5 \%-5.8 \%)$, repeat surgery (1.1\% to $5.6 \%)$, infection of the urinary tract $(3.6 \%-4.2 \%)$, bleeding requiring blood transfusions $(2.0 \%$ to $2.9 \%)$ and TUR syndrome $(0.8 \%-1.4 \%)$. In this series, the mortality rate was $0.10 \%$ and the short-term morbidity rate was $11.1 \%{ }^{3}$ In elderly patients on anticoagulant medication and antiplatelet drugs, the risk of TURP-related hemorrhage increases, necessitating the use of alternative sources of energy for $\mathrm{BPH} .^{4}$

The first study on photoselective vaporisation of the prostate (PVP) involving the GreenLight ${ }^{\mathrm{TM}} \mathrm{KTP}$ laser was published in 1998 by Malek et al. ${ }^{5}$ GreenLight ${ }^{\mathrm{TM}}$ laser emits radiation at a wavelength of $532 \mathrm{~nm}$. It is selectively absorbed in tissue by haemoglobin ('red' in colour), and has a penetration depth of $0.8 \mathrm{~mm}$. The tissue target chromophore is the haemoglobin molecule, and the laser is delivered using a side-firing, silica-based, fibre through a special visual 'scope.' PVP has been extensively studied with incrementally improved systems, the GreenLight ${ }^{\mathrm{TM}}$ HPS 120W system and in 2010, the GreenLight ${ }^{\mathrm{TM}}$ XPS

Please cite this article as follows: Akhtar OS, Raina S. A study of the role of 180W XPS lithium triborate laser in the treatment of patients with lower urinary tracts symptoms due to benign prostatic hyperplasia. J Lasers Med Sci. 2018;9(4):261-267. doi:10.15171/jlms.2018.47. 
180W systems (Boston Scientific, Marlborough, MA, USA). In the improvement of the XPS $180 \mathrm{~W}$ system, there was $50 \%$ increase in power, and a $50 \%$ increase in the laser beam, diameter, which kept power density the same as before ${ }^{6}$. Also added on were liquid cooling (with normal saline) of the fibre, an automatic system to shut down power with overheating of the fibre, and new coagulation settings that provided a pulsed as opposed to quasi-continuous low power mode. ${ }^{7}$ PVP has been used in patients taking oral anticoagulant medications and found to be safe. ${ }^{8,9}$ The mechanism of PVP relies on its photoselective absorption of oxyhemoglobin in the prostate, causing 'photovaporization' of the tissue of the prostate, reducing intra-operative bleeding. ${ }^{10}$

\section{Methods}

Study Population

Thirty-four patients, who were diagnosed with LUTS due to $\mathrm{BPH}$, were operated upon using the GL-XPS system. One of 4 experienced surgeons performed all the procedures, done between July 2013 and June 2015. All data was collected and recorded prospectively.

Surgery indications were based on criteria set by the American Urological Association ${ }^{11}$ and the European Association of Urology. ${ }^{2}$ The baseline parameters and surgery outcomes were collected (Tables 1 and 2). Patients on anticoagulant medication and those who were catheterized before surgery or had a history of urinary retention were also included. Patients on aspirin (acetylsalicylic acid) were asked to continue taking the medication. We excluded patients with bladder neck stenosis or urethral stricture, suspected prostatic malignancy, bladder tumours, neurogenic bladder.

The surgical procedures were performed as per the steps given by International GreenLight ${ }^{\mathrm{TM}}$ Users group. ${ }^{12}$ GreenLight $^{\mathrm{TM}}$ XPS was used throughout the procedure, and pure vaporization was used. The irrigant was room temperature normal saline which was used in a $24 \mathrm{~F}$ laser cystoscope. The highest power setting reached was $180 \mathrm{~W}$, adjusted in 10W steps.

Assessment

Standard parameters related to prostate surgery and

Table 1. Patient Characteristics

\begin{tabular}{ll}
\hline Age, years (range) & $68.74(53-87)$ \\
\hline PSA, ng/dL (range) & $2.51(0.6-6.15, \mathrm{SD}=1.39)$ \\
\hline Prostate volume, mL (range) & $57.1(10-162, \mathrm{SD}=35.46)$ \\
Post-void residue (PVR), mL (range) & $137.8(0-916, \mathrm{SD}=201.1)$ \\
\hline Operating time, min (range) & $87(60-240, \mathrm{SD}=32.4)$ \\
Lasing time, min (range) & $44.23(25-130, \mathrm{SD}=18.62)$ \\
Applied energy, kJ (range) & $267(171-800, \mathrm{SD}=109)$ \\
IPSS pre-operative score (range) & $20.0(15-25, \mathrm{SD}=2.81)$ \\
\hline
\end{tabular}

complications of surgery and symptoms of patients were assessed prospectively, and one month after the surgery. In the preoperative assessment, prostate volume (mL), International Prostate Symptom Score (IPSS), and maximum urinary flow rate $(\mathrm{Qmax}, \mathrm{mL} / \mathrm{s})$ were measured. The preoperative assessments also included physical examination, and medical history, urine analysis and renal function tests, a serum prostate-specific antigen level (PSA, ng/mL), and serum electrolytes. Patients with suspicious DRE's and/or high PSA levels were further evaluated for carcinoma of the prostate $(\mathrm{CaP})$ prior to subjecting them to GreenLight ${ }^{\mathrm{TM}}$ Laser PVP, in the form of biopsy. The intraoperative readings recorded were total lasing time ( $\mathrm{min})$, total energy usage $(\mathrm{kJ})$, as well as total operating time ( $\mathrm{min}$ ), measured from start of cystoscopy to insertion of catheter.

\section{Statistical Analysis}

Statistical analysis was performed using the Google Sheets online software. For numerical data, independent $t$ tests were performed. To compare two sets of before and after surgery data, a paired $t$ test was used. Categorical data was analysed using the chi-square test. We took a $P$ value of $<0.05$ as statistically significant. Statistical results were shown as mean with standard deviation (SD) as a percentage of total patients.

\section{Number of Patients}

A total of 37 patients underwent the GreenLight ${ }^{\mathrm{TM}}$ Laser PVP at Jaslok Hospital between May 2013 and May 2015. Three patients were excluded from the study because of suspected carcinoma. The average age was 68.74 years. There was one Arab patient, the rest were of Indian ethnicity.

Table 2. Characteristics of Patients

\begin{tabular}{lc}
\hline Number (n) & 34 \\
\hline Average IPSS & $20(15-25, \mathrm{SD}=2.81)$ \\
\hline History of retention & $9 / 34(24 \%)$ \\
\hline Catheterised on admission & $9 / 34(24 \%)$ \\
\hline Duration of catheterisation (days) & $29(2-100, \mathrm{SD}=20.57)$ \\
\hline Urinary tract infection & $5 / 34(16 \%)$ \\
\hline Diabetes & $9 / 34(26 \%)$ \\
\hline Heart disease & $13 / 34(38 \%)$ \\
\hline Hypertension & $16 / 34(47 \%)$ \\
\hline Antiplatelet medication & $14 / 34(41 \%)$ \\
\hline Aspirin (acetylsalicylic acid) & $14 / 34(41 \%)$ \\
\hline Clopidogrel & $11 / 34(31 \%)$ \\
\hline H/o TURP & $3 / 34(9 \%)$ \\
\hline Bladder wall thickness (mm) & 4.5 \\
\hline ASA Class III \& IV & $18(54 \%)$ \\
\hline
\end{tabular}




\section{Symptoms}

Patients presented due to LUTS. They were evaluated using the IPSS score. The average IPSS score was 20 , range 15-25. A total of 9 patients had a history of retention of urine. The average number of episodes of retention was 1.55. Nine patients were catheterised on admission.

\section{History of Surgeries}

Fifteen patients (44\%) had undergone some type of surgery. Pertinently, 3 (9\%) had undergone TURP in the past.

\section{Admission Status}

Two (6\%) patients were referred to the Urology Department from Intensive Care (ICU) for their symptoms. The rest were scheduled admissions for planned procedures.

\section{Examination Findings}

The 2 patients referred from ICU were unstable; one of them required continuous oxygen and had a poor left ventricular function of $15 \%$. The other had undergone an angioplasty recently and was on vasopressor support for stabilisation. The rest of the patients were stable on admission.

None of the patients had a palpable bladder on examination in hospital. The DRE findings of patients in this study were not suspicious for malignancy. A total of 4 patients (12\%) had Grade I prostatomegaly (Upper border of prostate easily reached), 26 (76\%) had Grade II prostatomegaly (Upper border reached with difficulty) and $4(12 \%)$ had Grade III prostatomegaly (Upper border not reached)

\section{Investigations}

The haemoglobin $(\mathrm{Hb})$ levels for the patients ranged from $8 \mathrm{~g} / \mathrm{dL}$ to $17 \mathrm{~g} / \mathrm{dL}$, with an average of $12.78 \mathrm{~g} / \mathrm{dL}$. Four patients (12\%) had $\mathrm{Hb}$ levels of $<10 \mathrm{~g} / \mathrm{dL}$. The average packed cell volume (PCV) was 38.8 (Range 25-50). The average platelet count was 252000/dL (Range 150000450000 ). Serum creatinine levels averaged $1.14 \mathrm{mg} / \mathrm{dL}$, with a range of $0.7 \mathrm{mg} / \mathrm{dL}-2.7 \mathrm{mg} / \mathrm{dL}$.

\section{PSA Levels}

The average PSA levels were 2.5, with a range of 0.5-6.15 ng/dL. Four $(12 \%)$ of patients had a PSA level of $>4.0$. One patient with a PSA of 6.15 had a history of UTI at the time of measurement, and tissue taken during the procedure was negative for malignancy. One patient (PSA of 5.3) had undergone a TRUS guided biopsy which was negative, and the other two had reasonably large glands of sizes $130 \mathrm{~g}$ (PSA of 4.5), and $87 \mathrm{~g}$ (PSA of 5.9) respectively to offset the relatively high PSA level.

\section{Prostate Size}

The average size of the prostate was $57.0 \mathrm{~g}$, with a range from 10-162 g. Eight patients (24\%) had prostates of $>80 \mathrm{~g}$ size.

Post-void Residue and Bladder Findings

The average post-void residue (PVR) was $137.8 \mathrm{~mL}$ (Range from 0-916 mL). Seventeen patients (50\%) had PVR of over $75 \mathrm{~mL}$. No patient had bladder diverticuli, and the average documented bladder wall thickness was $4.5 \mathrm{~mm}$ (range $3.5-6.0 \mathrm{~mm}$ )

\section{Surgery Characteristics}

Duration of Surgery

The average duration of surgery was 1.27 hours, or 76 minutes, including anaesthesia time. The range was from 1 hour to 4 hours.

\section{Energy Used}

The average energy used across all cases was $267.2 \mathrm{~kJ}$ per case. In cases where the size of the prostate was $>80 \mathrm{~g}$ $(n=8)$, the energy used averaged $390 \mathrm{~kJ}$ per case.

\section{Fibres Used}

The advantage of having the 180W XPS system remains the ability to deliver high amounts of energy in low periods of time with reliability. We used 1.02 fibres per case, with only one (3\%) of cases requiring more than one fibre.

\section{Lasing Time}

The average lasing time was 44.2 minutes per case, with a range from 25-130 minutes.

\section{Postoperative Characteristics}

In all patients, there was mild haematuria postoperatively. In 5 patients (15\%) irrigation had to continue more than 24 hours. Four $(80 \%)$ of these patients were anticoagulated. Seven patients $(21 \%)$ had their catheters removed on day 1 , and 22 patients $(64 \%)$ were still catheterised after 24 hours, but without any irrigation, and the urine was clear (Table 3).

\section{Catheter Removal}

The average duration of catheterisation was 1.91 days, or 40.17 hours. Seven $(21 \%)$ patients had their catheters removed on day 1 , in $23(67.7 \%)$ patients catheter was removed on day 2 , and 4 (12\%) had their catheters removed on day 3. No patient was postoperatively catheterised beyond day 3, unless catheter had been removed and patient was re-catheterised because of retention. Three (9\%) patients did not pass urine after removal of catheter, they required re-catheterisation.

\section{Other Characteristics}

Dysuria was reported by 6 (18\%) patients (Clavien Dindo Scale (CS) 0). Frequency (having to go to pass urine every $<2$ hours) was seen in $24(70.6 \%)$ patients (CS 0), urgency (without bacteriuria, not treated) was seen in $6(18 \%)$ 
Table 3. A List of Adverse Events Based on Peyronnet et al ${ }^{16}$

\begin{tabular}{|c|c|c|}
\hline $\begin{array}{l}\text { Clavien Dindo } \\
\text { Grade }\end{array}$ & Complication & No. of AEs \\
\hline \multirow{6}{*}{1} & Dysuria & 5 \\
\hline & Frequency & 25 \\
\hline & Urgency & 7 \\
\hline & Haematuria & 2 \\
\hline & $\begin{array}{l}\text { Retention of urine postoperatively in } \\
\text { patient with urinary catheter previously }\end{array}$ & 1 \\
\hline & $\begin{array}{l}\text { Retention of urine postoperatively } \\
\text { in patient without urinary catheter } \\
\text { previously }\end{array}$ & 2 \\
\hline \multirow{3}{*}{2} & $\begin{array}{l}\text { Storage symptoms requiring treatment } \\
\text { on discharge }\end{array}$ & 1 \\
\hline & Sepsis & 0 \\
\hline & Blood transfusion & 0 \\
\hline \multirow{2}{*}{3} & Gross haematuria requiring cystoscopy & 0 \\
\hline & Rectal wound & 0 \\
\hline \multirow{3}{*}{$4 a$} & Severe sepsis & 0 \\
\hline & Acute renal failure & 0 \\
\hline & Haemorrhagic shock & 0 \\
\hline $4 b$ & Acute respiratory failure & 0 \\
\hline 5 & Death & 0 \\
\hline
\end{tabular}

Abbreviation: $\mathrm{AE}$, adverse event.

patients (CS 0), retention in 3 (9\%) patients (CS 1), and gross haematuria in $2(6 \%)$ patients (CS 1$)$ (Table 3 ).

Postoperative Symptoms

An average drop in IPSS score (measured 30 days after discharge) of 8.7 was noted on follow-up (Range 5-13).

Total Admission Days

Mean admission duration was 3.5 days (range: 2-6 days). No patient stayed longer than 6 days postoperatively. Most $(26,82 \%)$ patients were admitted a day before surgery, or were already admitted $(2,6 \%)$ for evaluation and optimisation in view of comorbidities. Only 6 (12\%) were admitted on the day of surgery, and the average admission stay was 2 days in this group.

\section{Discussion}

To the best of the author's knowledge, this is the first case series published on Laser PVP using an XPS 180W from an Indian setup.

Age

The average age of the patients in our study was 68.7 years. It compares favourably with the average age of 65.4 years in the GOLIATH Trial, ${ }^{13}$ of 70.7 years in the Bachmann et $\mathrm{al}^{14}$ study of 201 consecutive cases, and of 68.9 years in the paper by Hueber et $\mathrm{al}^{15}$ (cohort undergoing Laser PVP using XPS 180W).

In our study, age was not found to be an independent risk factor for complications, which was also determined in the study by Peyronnet et al. ${ }^{16}$

\section{Symptoms}

The average IPSS score in our patients was 20 which is slightly lower than some contemporary studies. In the GOLIATH Trial ${ }^{13}$ the average IPSS score was 21.2 in the GreenLight $^{\mathrm{TM}}$ group, in the series by Ben-Zvi et $\mathrm{al}^{17}$ the average IPSS score was 24.2 and in the study by Eken et a ${ }^{10}$ the average IPSS of patients who had Laser PVP with XPS $180 \mathrm{~W}$ was 23.8 .

\section{Antiplatelet Medications}

Patients on acetylsalicylic acid (aspirin): In our study 14 (41\%) of patients were on aspirin. No patient required blood transfusion perioperatively in our study. Five out of 27 patients had their catheter in place on day 2 and required saline irrigation to keep their urine clear. All these 5 (100\%) were on Aspirin perioperatively which could not be stopped because of comorbidities. Of the 2 patients in our study who developed haematuria after catheter removal, requiring conservative treatment neither was on aspirin/clopidogrel.

This compares well with the GOLIATH trial, ${ }^{13}$ where in $28 / 134$ patients $(20.9 \%)$ were on aspirin perioperatively. In the study by West and Woo, ${ }^{18} 24$ (17.5\%) of 137 patients treated by XPS $180 \mathrm{~W}$ were anticoagulated. In their study of 201 consecutive patients Bachmann et $\mathrm{al}^{14}$ had 55/201 patients (27.4\%) who were on aspirin. They did not report any specific complications to this patient group.

\section{Patients on Clopidogrel}

A total of 11 out of 34 (32.5\%) patients in our study were on clopidogrel at the time of surgery. No patient in this group required blood transfusions postoperatively. One out of $3(33 \%)$ patients who developed postoperative retention was on clopidogrel and aspirin. This patient required catheterisation and bladder washes for treatment of the retention.

\section{PSA Level}

The average PSA level of our patients was 2.51. In the GOLIATH trial ${ }^{13}$ the PSA was 2.7 in the cohort of patients who underwent XPS 180W. The PSA level in the study by Eken et $\mathrm{al}^{10}$ the PSA level was 2.79 in the patients undergoing the XPS 180W Laser PVP.

\section{Relationship of PSA Level to Complications}

Our study did not show any statistically significant relationship between the PSA levels and postoperative complications.

Prostate Size

The impact of prostate size on surgical outcomes has been studied in previous papers. West and Woo $^{18}$ concluded 
that there was no increase in the complication rate with increasing prostate size.

Hueber et $\mathrm{al}^{19}$ studied the impact of preoperative size of the prostate on safety and outcome of surgery. Median prostate size was $50 \mathrm{~mL}$ ( $\mathrm{n}=387$ patients) vs $108 \mathrm{~mL}$ ( $\mathrm{n}=741$ patients) in the groups prostate volume $(\mathrm{PV})<80$ $\mathrm{mL}$ vs $\mathrm{PV} \geq 80 \mathrm{~mL}$ respectively. Conversion to TURP was significantly higher in the $\geq 80 \mathrm{~mL}$ prostate group with a rate of $8.4 \%$ compared to $0.6 \%$ in the $<80 \mathrm{~mL}$ prostate group $(P<0.01)$. In this study, the average fibre usage was $1.1 /$ case in the $<80 \mathrm{~mL}$ group, and $1.5 /$ case in the $>80 \mathrm{~mL}$ group. Duration of hospital stay was almost similar in the two groups (Tables 4 and 5).

\section{Duration of Catheterisation}

The average duration of catheterisation in our study was 1.91 days, or 40.17 hours. This compares favourably with the GOLIATH study ${ }^{13}$ in which the average catheter duration was 40.8 hours in 128 patients of the XPS$180 \mathrm{~W}$ arm. In the study by Hueber et $\mathrm{al}^{19}$ the catheterised duration was 26 hours in the patients who had PV $<80$ $\mathrm{mL}$ and was 34 hours in the patients who had PV $>80$ $\mathrm{mL}$. In the study by Eken et al, ${ }^{10}$ the average catheterised duration was 17.8 hours for the patients who underwent the XPS-180W.

Blood Transfusions

There were no blood transfusions in any of our patients in this study. In the study by Hueber et $\mathrm{al},{ }^{19}$ no patient required a transfusion. Bachmann et a ${ }^{14}$ also reported no blood transfusions in their series of 201 patients. In the GOLIATH Trial, ${ }^{13}$ there was none in the XPS-180W arm.

\section{Reduction in IPSS Score}

The average fall in IPSS score in our study was 8.7 per case at 1 month follow-up. The 30 days mean IPSS score in our patient population was 11.35. Similar observations have been noted by Bachmann et al ${ }^{14}$ who noted a fall of 11.5 in his study at 1 month follow-up, with a mean IPSS score of 8.1 and in the GOLIATH Trial ${ }^{13}$ where the average fall was 9.3 in the XPS group at 3 weeks follow-up with a mean
Table 5. Comparison of the 2 Groups in Our Study

\begin{tabular}{lccc}
\hline Parameters & Group I & ${\text { Group } \text { II }^{\mathrm{b}}}^{\mathrm{a}}$ & $\boldsymbol{P}^{\text {Value }}$ \\
\hline Prostate size average $(\mathrm{mL})$ & 40.4 & 111.3 & 0.07 \\
Lasing time, average $(\mathrm{min})$ & 38.1 & 64.6 & 1.0 \\
Energy used $(\mathrm{kJ})$ ), average & 229.4 & 390 & 0.98 \\
Fibres used & $1.0 /$ case & $1.12 /$ case & 0.16 \\
\hline
\end{tabular}

a Prostate size $<80 \mathrm{~mL}(\mathrm{n}=26)$.

b Prostate size $>80 \mathrm{~mL}(\mathrm{n}=8)$.

'There was no statistically significant difference between the two groups in our study $(P<0.05$ significant).

IPSS score of 11.9. Eken et $\mathrm{al}^{10}$ showed a drop in IPSS at 6 months of 15.46 (2-24).

\section{High-Risk Patients}

A total of 18 patients in our study were high surgical risk patients, defined as ASA class 3 or 4 . The outcomes of those patients were comparable; there were no Clavien Dindo Class $4 \mathrm{a}, 4 \mathrm{~b}$, or 5 complications in these patients. The statistical analysis of the duration of stay and adverse effects of the patients based on ASA class failed to show any significant difference between the two groups, showing that XPS-180W was safe in the high-risk patients in our study.

\section{Total Admission Days}

Average duration of admission in our study was 3.5 days, more than the average of 24 hours in the study of Hueber et al. ${ }^{19}$ It compares favourably with the patients enrolled in the XPS-180W arm of the GOLIATH Trial, ${ }^{13}$ with an average stay of 65.5 hours (2.7 days) (Table 6).

Table 6. Comparison of Duration of Admission Between Our Study and Other Studies

\begin{tabular}{lcc}
\hline Study, year & $\begin{array}{c}\text { Patients who } \\
\text { underwent XPS- } \\
\mathbf{1 8 0 W}(\mathbf{n})\end{array}$ & $\begin{array}{c}\text { Mean duration } \\
\text { of hospital stay } \\
\text { (days) }\end{array}$ \\
\hline GOLIATH, 2014 & 134 & 2.7 \\
Benejam-Gaul et $\mathrm{al}^{20}$, 2014 & 39 & 1.3 \\
Hueber et al, ${ }^{19}$ 2015 & 1196 & 1.0 \\
Our study, 2013-2015 & 34 & 3.5 \\
\hline
\end{tabular}

Table 4. Surgical Characteristics of Patients With Prostate Sizes $>80 \mathrm{~mL}$

\begin{tabular}{|c|c|c|c|c|}
\hline Number & Prostate Size $(\mathrm{mL})$ & Lasing Time (min) & Energy Used (kJ) & Fibres Used \\
\hline 1 & 130 & 75 & 400 & 1 \\
\hline 2 & 162 & 130 & 800 & 2 \\
\hline 3 & 87 & 48 & 320 & 1 \\
\hline 4 & 100 & 55 & 350 & 1 \\
\hline 5 & 84 & 50 & 300 & 1 \\
\hline 6 & 113 & 59 & 370 & 1 \\
\hline 7 & 100 & 52 & 280 & 1 \\
\hline 8 & 115 & 48 & 300 & 1 \\
\hline Patients $n=8$ & Average size $=111.3 \mathrm{~mL}$ & Average lasing time $=64 \mathrm{~min}$ & $\begin{array}{l}\text { Average energy used }=390 \mathrm{~kJ} / \\
\text { case }\end{array}$ & $\begin{array}{c}\text { Average number of fibres }=1.12 / \\
\text { case }\end{array}$ \\
\hline
\end{tabular}




\section{Limitations}

The limitations of this study were a small sample size and its non-randomised design. There was no comparison with TURP. The surgeons who participated in this study were proficient in 120W-HPS Green Light Laser techniques, and this study may not reflect a learning curve that may occur when the XPS-180W is introduced in a setting previously inexperienced with $120 \mathrm{~W}-\mathrm{HPS}$.

\section{Conclusion}

Our study shows that XPS-180W is a safe, efficacious method and that it can be used for the treatment of patients with LUTS due to BPH. It has also demonstrated efficacy in patients who are on antiplatelet medications even up to and during the surgery. Rates of haematuria, postoperative retention and blood transfusions were low. Our study also showed that XPS-180W can be potentially used in large prostates $(>80 \mathrm{~mL})$ hitherto not considered optimal cases for minimal access techniques. We had a total of 18 (53\%) high surgical risk (ASA class 3,4) patients in our study, and there was no significant difference in outcome in this group using the XPS-180W when compared with the ASA class 2 patients, proving it to be safe.

\section{Conflict of Interests}

The authors have no conflict of interest.

\section{Ethical Considerations}

The Institutional Ethics Board approval of the study was obtained.

\section{Acknowledgements}

The authors would like to thank the Department of Urology at Jaslok Hospital \& Research Centre for their kind help during this study, with special thanks to Dr A A Raval, Dr Percy Chibber, Dr A Vaze, and Dr P F Soonawalla.

\section{References}

1. Chapple CR, Roehrborn CG. A shifted paradigm for the further understanding, evaluation, and treatment of lower urinary tract symptoms in men: focus on the bladder. Eur Urol. 2006;49(4):651-658. doi:10.1016/j. eururo.2006.02.018

2. Oelke M, Bachmann A, Descazeaud A, et al. EAU guidelines on the treatment and follow-up of nonneurogenic male lower urinary tract symptoms including benign prostatic obstruction. Eur Urol. 2013;64(1):118-140. doi:10.1016/j.eururo.2013.03.004

3. Reich O, Gratzke C, Bachmann A, et al. Morbidity, mortality and early outcome of transurethral resection of the prostate: a prospective multicenter evaluation of 10,654 patients. J Urol. 2008;180(1):246-249. doi:10.1016/j.juro.2008.03.058

4. Kavanagh LE, Jack GS, Lawrentschuk N. Prevention and management of TURP-related hemorrhage. Nat Rev Urol. 2011;8(9):504-514. doi:10.1038/nrurol.2011.106
5. Malek RS, Barrett DM, Kuntzman RS. High-power potassium-titanyl-phosphate $\quad(\mathrm{KTP} / 532) \quad$ laser vaporization prostatectomy: 24 hours later. Urology. 1998;51(2):254-256.

6. Zorn KC, Liberman D. GreenLight 180W XPS photovaporization of the prostate: how I do it. Can J Urol. 2011;18(5):5918-5926.

7. Campbell NA, Chung AS, Yoon PD, Thangasamy I, Woo HH. Early experience photoselective vaporisation of the prostate using the $180 \mathrm{~W}$ lithium triborate and comparison with the $120 \mathrm{~W}$ lithium triborate laser. Prostate Int. 2013;1(1):42-45. doi:10.12954/pi.12006

8. Bouabdallah Z, Kharbouchi A, Colau A, Cariou G. [Prostate laser photovaporisation in patients at high risk of bleeding]. Pan Afr Med J. 2013;16:2. doi:10.11604/ pamj.2013.16.2.2853

9. Ruszat R, Wyler S, Forster T, et al. Safety and effectiveness of photoselective vaporization of the prostate (PVP) in patients on ongoing oral anticoagulation. Eur Urol. 2007;51(4):1031-1038. doi:10.1016/j. eururo.2006.08.006

10. Eken A, Soyupak B, Acil M, Arpaci T, Akbas T. Safety, efficacy and outcomes of the new GreenLight XPS 180W laser system compared to the GreenLight HPS 120W system for the treatment of benign prostatic hyperplasia in a prospective nonrandomized single-centre study. Can Urol Assoc J. 2015;9(1-2):e56-60. doi:10.5489/ cuaj.2263

11. McVary KT, Roerhborn CG, Avins AL, et al. American Urological Association Guideline: Management of Benign Prostatic Hyperplasia. American Urological Association; 2010.

12. Muir G, Gomez Sancha F, Bachmann A, et al. Techniques and Training with GreenLight HPS 120-W Laser Therapy of the Prostate: Position Paper. Eur Urol Suppl. 2008;7(4):370-377. doi:10.1016/j.eursup.2008.01.012

13. Bachmann A, Tubaro A, Barber N, et al. A European multicenter randomized noninferiority trial comparing 180 W GreenLight XPS laser vaporization and transurethral resection of the prostate for the treatment of benign prostatic obstruction: 12-month results of the GOLIATH study. J Urol. 2015;193(2):570-578. doi:10.1016/j.juro.2014.09.001

14. Bachmann A, Muir GH, Collins EJ, et al. 180-W XPS GreenLight laser therapy for benign prostate hyperplasia: early safety, efficacy, and perioperative outcome after 201 procedures. Eur Urol. 2012;61(3):600607. doi:10.1016/j.eururo.2011.11.041

15. Hueber PA, Liberman D, Ben-Zvi T, et al. $180 \mathrm{~W}$ vs $120 \mathrm{~W}$ lithium triborate photoselective vaporization of the prostate for benign prostatic hyperplasia: a global, multicenter comparative analysis of perioperative treatment parameters. Urology. 2013;82(5):1108-1113. doi:10.1016/j.urology.2013.03.059

16. Peyronnet B, Pradere B, Brichart N, Bodin T, Bertrand P, Bruyere F. Complications associated with photoselective vaporization of the prostate: categorization by a panel of GreenLight users according to Clavien score and report of a single-center experience. Urology. 2014;84(3):657664. doi:10.1016/j.urology.2014.05.028 
17. Ben-Zvi T, Hueber PA, Liberman D, Valdivieso R, Zorn KC. GreenLight XPS 180W vs HPS $120 \mathrm{~W}$ laser therapy for benign prostate hyperplasia: a prospective comparative analysis after 200 cases in a single-center study. Urology. 2013;81(4):853-858. doi:10.1016/j. urology.2012.12.031

18. West KE, Woo HH. Does prostate size impact upon perioperative outcomes associated with photoselective vaporization of the prostate using the $180 \mathrm{~W}$ lithium triborate laser? Urol Ann. 2015;7(1):17-20. doi:10.4103/0974-7796.148579

19. Hueber PA, Bienz MN, Valdivieso R, et al. Photoselective
Vaporization of the Prostate for Benign Prostatic Hyperplasia Using the 180 Watt System: Multicenter Study of the Impact of Prostate Size on Safety and Outcomes. J Urol. 2015;194(2):462-469. doi:10.1016/j. juro.2015.03.113

20. Benejam-Gual JM, Sanz-Granda A, Budia A, Extramiana J, Capitan C. Multicenter study on costs associated with two surgical procedures: GreenLight XPS $180 \mathrm{~W}$ versus the gold standard transurethral resection of the prostate. Actas Urol Esp. 2014;38(6):373-377. doi:10.1016/j. acuro.2013.10.011 